\title{
The surface adsorption of some hospital airborne microorganisms by nano-based columns
}

\author{
M. R. Mirjalili ${ }^{1} \cdot$ S. Hekmatimoghaddam ${ }^{2} \cdot$ I. Rezapour $^{2} \cdot$ S. Khosravi ${ }^{2}$ \\ A. Shojaee ${ }^{3}$ A. Jebali ${ }^{2}$
}

Received: 17 July 2015/Revised: 4 September 2015/Accepted: 21 September 2015/Published online: 1 October 2015

(C) Islamic Azad University (IAU) 2015

\begin{abstract}
The aim of this study was to evaluate the adsorption of some hospital airborne microorganisms, e.g. Staphylococcus aureus, Streptococcos pyogenes, Pseudomonas aeruginosa, and Candida albicans by some inorganic nanoparticles. First, each microbial suspension $\left(2 \times 10^{4}\right.$ and $\left.2 \times 10^{6} \mathrm{CFU} / \mathrm{mL}\right)$ was separately added to adsorbent columns ( 1 and $2 \mathrm{~g}$ ), containing $\mathrm{CaSO}_{4}, \mathrm{CaCO}_{3}$, and $\mathrm{FeSO}_{4}$ nanoparticles. Then, the colony count reduction was measured for each adsorbent column. This study showed that all nanoparticles could adsorb all kinds of microorganisms. Importantly, the combination of $\mathrm{CaSO}_{4}$ and $\mathrm{CaCO}_{3}$ nanoparticles led to better adsorption property. Moreover, it was found that the adsorption was related to adsorbent weight and microbial density. The authors suggest that these adsorbent columns are good choice to remove hospital airborne microorganisms.
\end{abstract}

Keywords Adsorption - Airborne $\cdot$ Microorganisms · Adsorbent column $\cdot$ Nanoparticles

A. Jebali

alijebal2011@gmail.com

1 Department of Internal Medicine, Shahid Sadoughi University of Medical Sciences, Yazd, Iran

2 Department of Laboratory Sciences, School of Paramedicine, Shahid Sadoughi University of Medical Sciences, Yazd 8916733754, Iran

3 Department of Anesthesia and Operation, School of Paramedicine, Shahid Sadoughi University of Medical Sciences, Yazd, Iran

\section{Introduction}

Hospital-acquired infections or nosocomial infections are induced by different pathogens, e.g. Staphylococcus aureus, Candida albicans, Pseudomonas aeruginosa, Streptococcos pyogenes, found in hospital environment. These infections can be acquired by a patient during a hospital visit. Approximately, 1.7 million hospital-associated infections have been reported by the Centers for Disease Control (CDC), in USA (Kelly and Monson 2012; Lobdell et al. 2012).

Nowadays, air filtration systems are applied in hospital to remove virus, bacteria, fungi, pollen grains, and dusts. Basically, the concentration of airborne particles in a hospital is a balance between the rate of their release and the rate of their removal. Theoretically, air filters must remove particles before the reenter the hospital. Pollen grains, dusts, and fungal spores are not pathogenic, but can cause allergic rhinitis and asthma. All of them can be removed by traditional air filtration. Of airborne particles, viruses are too small, below $0.1 \mu \mathrm{m}$, and escape from micron-size pores. Based on CDC guidelines, a hospital air filtration system can play an important role in airborne particles. The most of air filtration systems are combined with UV lamp to kill captured microbes (Karottki et al. 2013; Ma and Henderson 2013; Wichmann et al. 2013).

In the most developing and undeveloped countries, no qualified air filtration system is used in the hospitals, because of bad hospital management and high price of air filtration systems. On the other hand, the sub-micron particles cannot be removed by traditional air filtration systems. Nanoparticles have high surface area and can be conjugated by different chemicals (Jung et al. 2011). We think that nanoparticles are good choice to adsorb airborne particles. They can be used as adsorbent column to remove 
both big particles, e.g. dusts, pollen grains, and fungi, and small particles, e.g. viruses and bacteria.

\section{Materials and methods}

\section{Materials}

$\mathrm{CaSO}_{4}, \mathrm{CaCO}_{3}$, and $\mathrm{FeSO}_{4}$ nanoparticles were provided from Zyst Fannavar Shargh Company, Iran. These nanoparticles had been characterized by scanning electron microscopy (SEM). Sabouraud dextrose agar (SDA), nutrient agar (NA), and RPMI1640 were purchased from Invitrogen, UK.

\section{Preparation of microbial suspension}

In this study, five microbial species were used, including Staphylococcus aureus, Streptococcos pyogenes, Pseudomonas aeruginosa, and Candida albicans. These isolates were obtained from Department of Microbiology, Paramedicine University, Shahid Sadoughi University of Medical Sciences, Yazd, Iran. One colony of Staphylococcus aureus, Streptococcos pyogenes, and Pseudomonas aeruginosa was inoculated on nutrient agar and incubated at $37{ }^{\circ} \mathrm{C}$ for $24 \mathrm{~h}$. In case of Candida albicans, one colony was inoculated on SDA and incubated at $25{ }^{\circ} \mathrm{C}$ for $48 \mathrm{~h}$. After incubation, all were washed by normal saline (NS). Finally, the density of each isolate was adjusted to $2 \times 10^{6} \mathrm{CFU} / \mathrm{mL}$ by NS .

\section{Preparation of adsorbent column}

The adsorbent column which used in this study had five layers (Fig. 1). Layers 1, 3, and 5 were cellulose, and layers 2 and 4 were adsorbent. Here, six adsorbents were prepared, including:

1. Adsorbent 1: Containing $\mathrm{CaSO}_{4}$ nanoparticles

2. Adsorbent 2: Containing $\mathrm{CaCO}_{3}$ nanoparticles

3. Adsorbent 3: Containing $\mathrm{FeSO}_{4}$ nanoparticles

4. Adsorbent 4: Containing $\mathrm{CaSO}_{4}$ and $\mathrm{CaCO}_{3}$ nanoparticles, at $50 \% \mathrm{w} / \mathrm{w}$

5. Adsorbent 5: Containing $\mathrm{CaSO}_{4}$ and $\mathrm{FeSO}_{4}$ nanoparticles, at $50 \% \mathrm{w} / \mathrm{w}$

6. Adsorbent 6: Containing $\mathrm{CaCO}_{3}$ and $\mathrm{FeSO}_{4}$ nanoparticles, at $50 \% \mathrm{w} / \mathrm{w}$

\section{Adsorption study}

Here, three individual experiments were done for each adsorbent column, including:

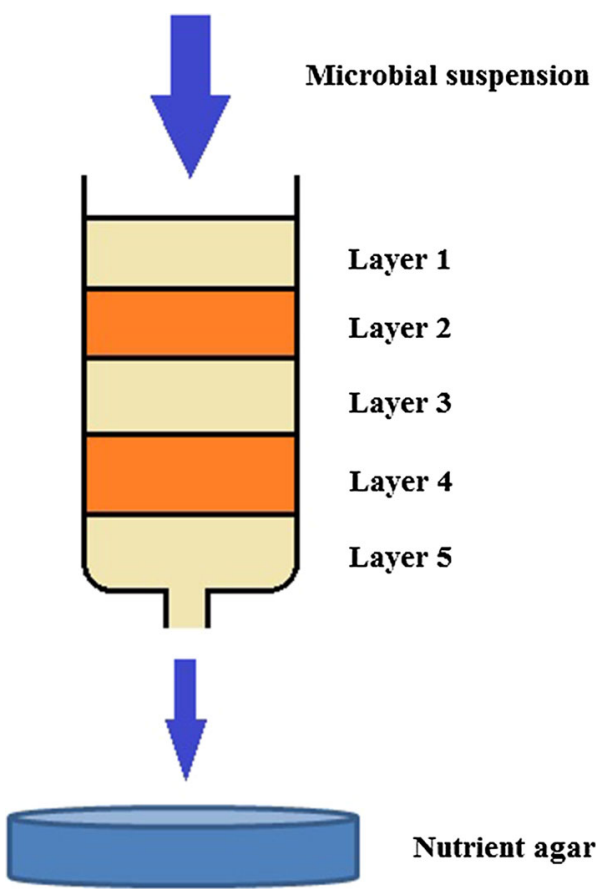

Fig. 1 Structure of adsorbent column used in this study. As seen, it had five layers. Layers 1, 3, and 5 were cellulose, and layers 2 and 4 were nanoparticles

A. Adsorbent column had $1 \mathrm{~g}$ nanoparticle, and the density of microbial suspension was $2 \times 10^{4} \mathrm{CFU} /$ $\mathrm{mL}$

B. Adsorbent column had $2 \mathrm{~g}$ nanoparticle, and the density of microbial suspension was $2 \times 10^{4} \mathrm{CFU} /$ $\mathrm{mL}$

C. Adsorbent column had $1 \mathrm{~g}$ nanoparticle, and the density of microbial suspension was $2 \times 10^{6} \mathrm{CFU} /$ $\mathrm{mL}$

First, $5 \mathrm{~mL}$ of microbial suspension was separately added to each adsorbent column. After $5 \mathrm{~min}$, the first droplet $(50 \mu \mathrm{L})$ which passed from column was collected, and then the quantity of microbes was read by cell counter. Finally, the percentage of colony count reduction was calculated, according to Formula 1.

Colony count reduction $=(A-B) \times 100 / B$

where $A$ is $\mathrm{CFU}$ of adsorbent column and $B$ is $\mathrm{CFU}$ of negative control. The column that had no nanoparticles was considered as negative control.

\section{Statistical analysis}

All tests were done three times, and the results are shown as the mean \pm standard deviation (SD). Parametric test (ANOVA) was applied to detect the significant difference. This test was carried out by SPSS software (V.16.0 for 
Windows; SPSS Inc., USA), and $P<0.05$ was considered as a significant difference.

\section{Results and discussion}

Figure 2 shows the SEM image of $\mathrm{CaSO}_{4}, \mathrm{CaCO}_{3}$, and $\mathrm{FeSO}_{4}$ nanoparticles. As seen, all had distribution size of $50 \pm 10 \mathrm{~nm}$, approximately. Figures $3 \mathrm{a}, \mathrm{b}, 4 \mathrm{a}, \mathrm{b}$, and 5a, b show the colony count reduction of microbial suspension when passed from adsorbent column 1, 2, 3, 4, 5, and 6, respectively. Here, the density of microbial suspension was $2 \times 10^{4} \mathrm{CFU} / \mathrm{mL}$, and the weight of adsorbent was variable, 1 and $2 \mathrm{~g}$. As the first finding, all adsorbent columns could adsorb all kinds of microorganisms which studied in this article. As the second finding, in all treated groups, adsorbent weight of $2 \mathrm{~g}$ was better than adsorbent weight of $1 \mathrm{~g}$, i.e. the more colony count reduction, the more adsorbent weight. As the third finding, the highest and least colony count reduction were achieved when microbial suspension was passed from adsorbent columns 4 and 3, respectively.

Figures $6 \mathrm{a}, \mathrm{b}, 7 \mathrm{a}, \mathrm{b}$, and $8 \mathrm{a}, \mathrm{b}$ show the colony count reduction of microbial suspension when passed from adsorbent columns 1, 2, 3, 4, 5, and 6, respectively. Here, the weight of adsorbent was $1 \mathrm{~g}$, and the density of microbial suspension was variable, $2 \times 10^{4}$ and $2 \times 10^{6} \mathrm{CFU} / \mathrm{mL}$. As an important result, the decrease in colony count reduction was observed when the density of microbial suspension was increased. Here, the highest and least colony count reductions were also achieved when microbial suspension was passed from adsorbent columns 4 and 3, respectively.

Staphylococcus aureus, Streptococcos pyogenes, Pseudomonas aeruginosa, and Candida albicans are the main cause of nosocomial infections (Gomes et al. 2014). These agents can spread in outdoor and outdoor air of hospital and lead to skin and lung infections (Pourakbari et al. 2015). Nowadays, some disinfectant agents are used to kill or inhibit nosocomial agents at hospital surfaces (Dancer
2014). But, it must be mentioned that these agents can be found in air, and surface disinfectant cannot damage them. The authors propose that the use of adsorbent materials is a key factor to remove them. Nanoparticles have a high surface area and can be attached to surface molecules of pathogens by non-covalent bindings (Daniel et al. 2014). In this study, we showed the adsorption property of $\mathrm{CaSO}_{4}$, $\mathrm{CaCO}_{3}$, and $\mathrm{FeSO}_{4}$ nanoparticles. Among them, $\mathrm{CaCO}_{3}$ nanoparticles had highest adsorption property, and $\mathrm{CaSO}_{4}$ nanoparticles had in the later level. This study showed that the combination of $\mathrm{CaSO}_{4}$ and $\mathrm{CaCO}_{3}$ nanoparticles led to better adsorption property. It must be noted the synergetic effect was also seen in the combination of $\mathrm{CaSO}_{4}$ and $\mathrm{FeSO}_{4}$ nanoparticles, and $\mathrm{CaCO}_{3}$ and $\mathrm{FeSO}_{4}$ nanoparticles. The aim of this study was to investigate the efficacy of $\mathrm{CaSO}_{4}, \mathrm{CaCO}_{3}$, and $\mathrm{FeSO}_{4}$ nanoparticles to adsorb Staphylococcus aureus, Streptococcos pyogenes, Pseudomonas aeruginosa, and Candida albicans. Here, six adsorbent columns were used, including $\mathrm{CaSO}_{4}$ nanoparticles, $\mathrm{CaCO}_{3}$ nanoparticles, $\mathrm{FeSO}_{4}$ nanoparticles, $\left(\mathrm{CaSO}_{4}+\mathrm{CaCO}_{3}\right)$ nanoparticles, $\left(\mathrm{CaSO}_{4}\right.$ and $\left.\mathrm{FeSO}_{4}\right)$ nanoparticles, and $\left(\mathrm{CaCO}_{3}\right.$ and $\left.\mathrm{FeSO}_{4}\right)$ nanoparticles. We found that all of them could adsorb microbes, i.e. all microorganisms which studied could be adsorbed by adsorbent column. Moreover, the best result was for adsorbent column 4 , with weight of $2 \mathrm{~g}$, and microbial suspension of $2 \times 10^{6} \mathrm{CFU} / \mathrm{mL}$. As mentioned, adsorbent column 4 had $\mathrm{CaSO}_{4}$ and $\mathrm{CaCO}_{3}$ nanoparticles, at $50 \%$ $\mathrm{w} / \mathrm{w}$. The surface adsorption of microbes by nanoparticles is an important finding. This phenomenon can be applied in manufacturing of adsorbent sheet or filter to remove microbes in important places, e.g. ICU and CCU. Nosocomial infections can be occurred in hospitals by both pathogenic and opportunistic microbes. It is important to control the quantity of microbes in air of hospitals.

Lukasik et al. investigated the effects of mono-, di-, and trivalent salts ( $\mathrm{NaCl}, \mathrm{MgCl} 2$, and $\mathrm{AlCl} 3$ ) on the adsorption of several viruses (MS2, PRD-1, fX174, and poliovirus 1) to microporous filters at different $\mathrm{pH}$ values. The increase in adsorption was observed when $\mathrm{AlCl} 3$ and $\mathrm{HCl}$ were added to
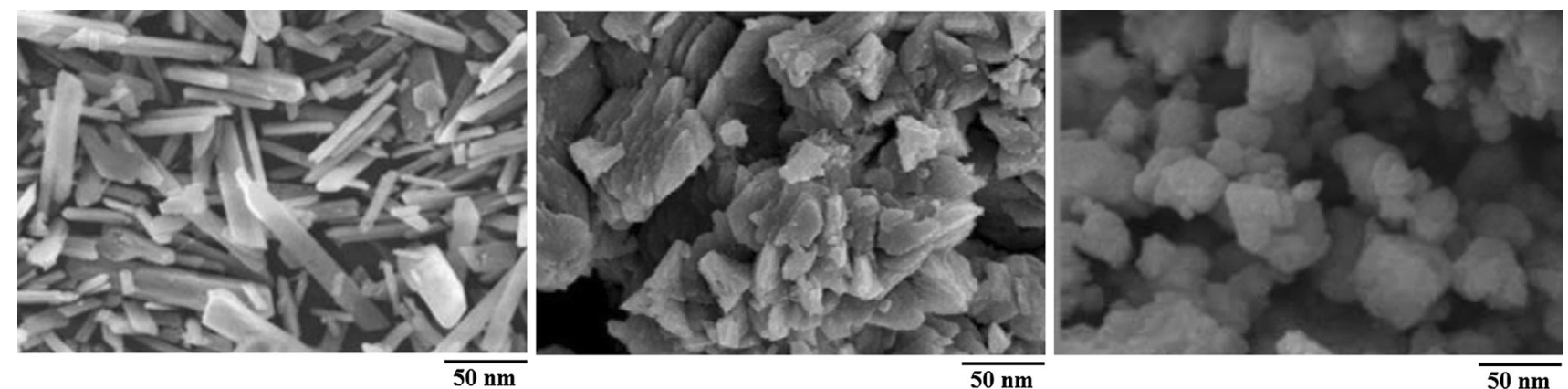

Fig. 2 SEM image of $\mathrm{CaSO}_{4}, \mathrm{CaCO}_{3}$, and $\mathrm{FeSO}_{4}$ nanoparticles 


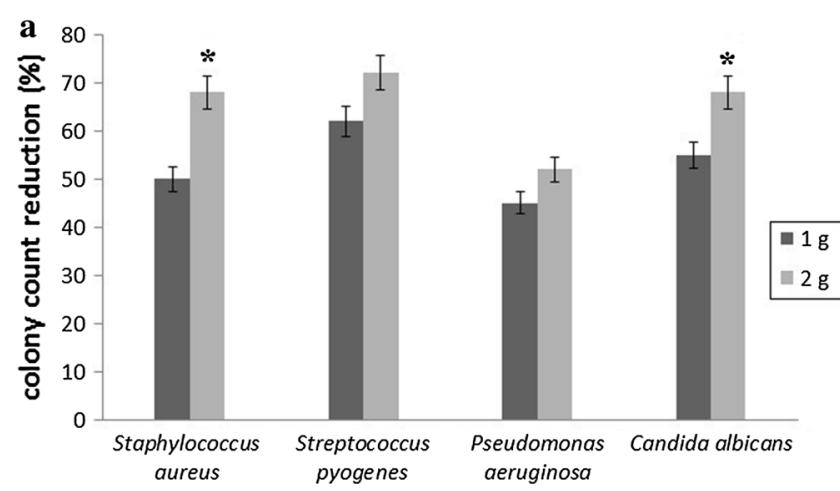

Fig. 3 Colony count reduction when microbial suspension was passed from adsorbent column 1 (a), 2 (b). Adsorbents 1 and 2 had $\mathrm{CaSO}_{4}$ and $\mathrm{CaCO}_{3}$ nanoparticles, respectively. Here, the density of

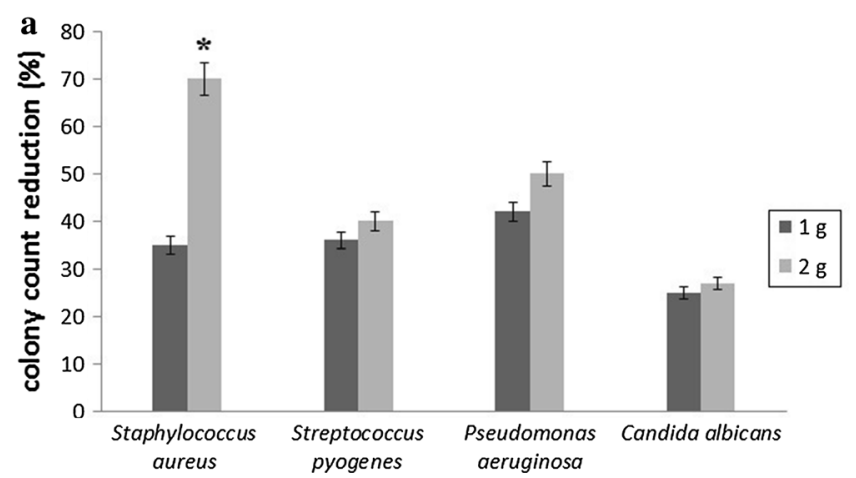

Fig. 4 Colony count reduction when microbial suspension was passed from adsorbent column 3 (a), 4 (b). Adsorbent 3 had $\mathrm{FeSO}_{4}$ nanoparticles, and adsorbent 4 had $\mathrm{CaSO}_{4}$ and $\mathrm{CaCO}_{3}$ nanoparticles.

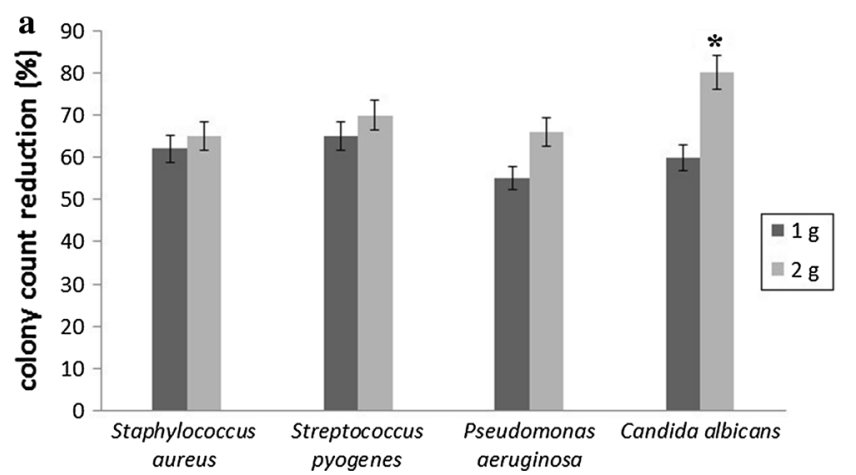

Fig. 5 Colony count reduction when microbial suspension was passed from adsorbent column 5 (a), 6 (b). Adsorbent 5 had $\mathrm{CaSO}_{4}$ and $\mathrm{FeSO}_{4}$ nanoparticles, and adsorbent 6 had $\mathrm{CaCO}_{3}$ and $\mathrm{FeSO}_{4}$

water which was resulted in the decrease in the $\mathrm{pH}$ of the water (Lukasik et al. 2000). Verdenelli et al. studied the activity of biostatic agents on the microbial colonization of panel filters. They showed the integrity of the filters and the lower release of microorganisms from treated filters

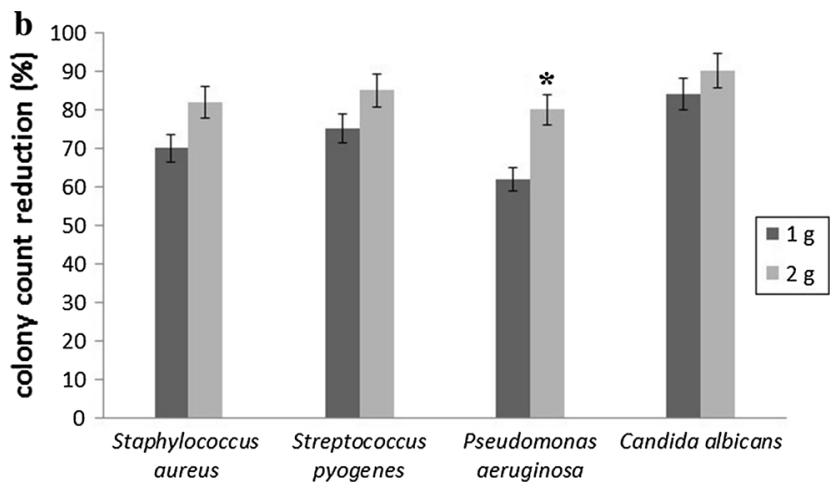

microbial suspension was $2 \times 10^{4}$, and the content of nanoparticles was variable, 1 and 2 g. $* P<0.05$ compared when the adsorbent had 1 g nanoparticles. $n=3$

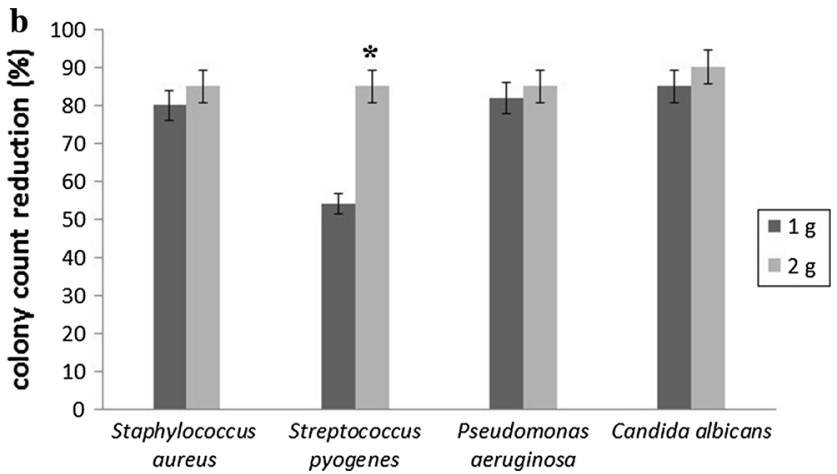

Here, the density of microbial suspension was $2 \times 10^{4}$, and the content of nanoparticles was variable, 1 and 2 g. $* P<0.05$ compared when the adsorbent had $1 \mathrm{~g}$ nanoparticles. $n=3$

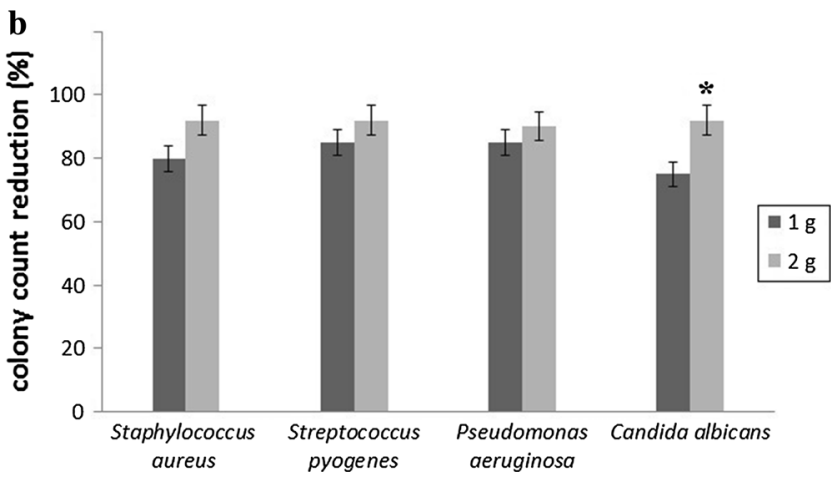

nanoparticles. Here, the density of microbial suspension was $2 \times 10^{4}$, and the content of nanoparticles was variable, 1 and $2 \mathrm{~g} . * P<0.05$ compared when the adsorbent had $1 \mathrm{~g}$ nanoparticles. $n=3$

(Verdenelli et al. 2003). Miaśkiewicz-Peska et al. used antimicrobial air filter treatment. They examined woven air filters made of polypropylene. It was found that antibacterial filter treatment resulted in an evident reduction in living bacterial cells (Miaśkiewicz-Peska and Łebkowska 2011). 


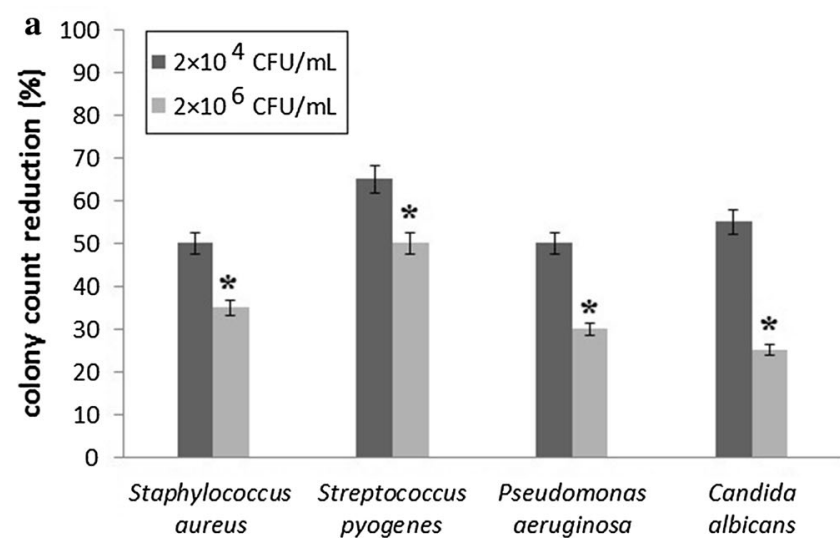

Fig. 6 Colony count reduction when microbial suspension was passed from adsorbent column 1 (a), 2 (b). Adsorbents 1 and 2 had $\mathrm{CaSO}_{4}$ and $\mathrm{CaCO}_{3}$ nanoparticles, respectively. Here, the content of

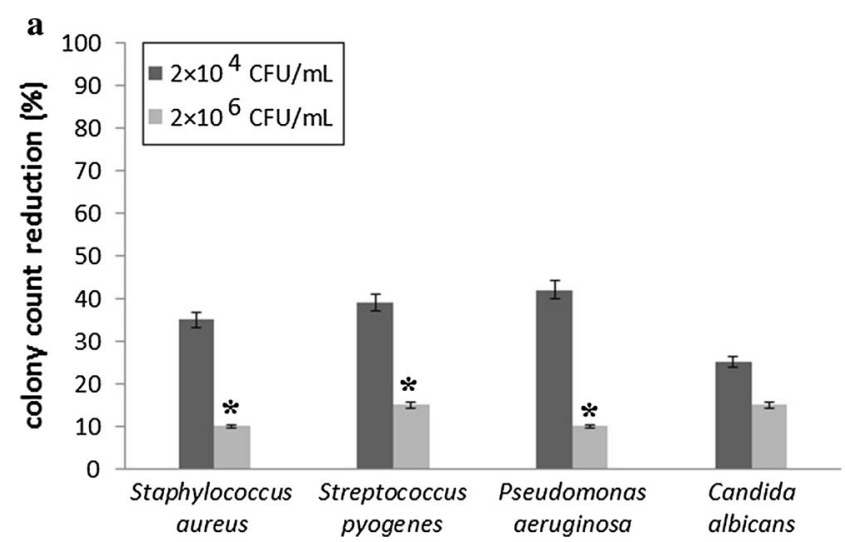

Fig. 7 Colony count reduction when microbial suspension was passed from adsorbent column 3 (a), 4 (b). Adsorbent 3 had $\mathrm{FeSO}_{4}$ nanoparticles, and adsorbent 4 had $\mathrm{CaSO}_{4}$ and $\mathrm{CaCO}_{3}$ nanoparticles. Here, the content of nanoparticles was $1 \mathrm{~g}$, and the density of

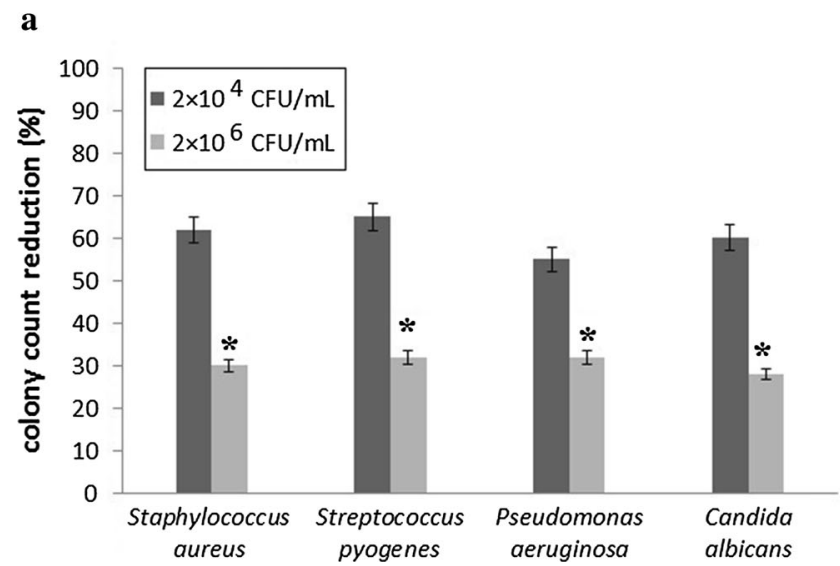

Fig. 8 Colony count reduction when microbial suspension was passed from adsorbent column 5 (a), 6 (b). Adsorbent 5 had $\mathrm{CaSO}_{4}$ and $\mathrm{FeSO}_{4}$ nanoparticles, and Adsorbent 6 had $\mathrm{CaCO}_{3}$ and $\mathrm{FeSO}_{4}$ nanoparticles. Here, the content of nanoparticles was $1 \mathrm{~g}$, and the

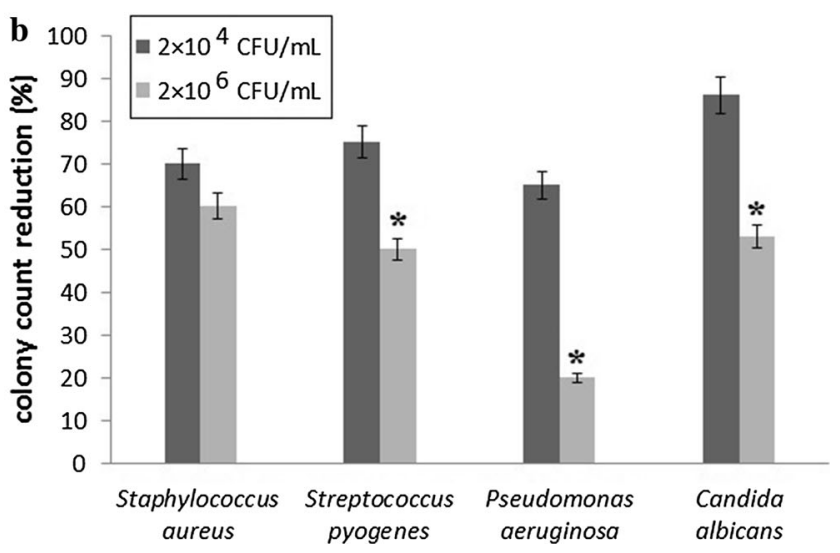

nanoparticles was $1 \mathrm{~g}$, and the density of microbial suspension was variable, $2 \times 10^{4}$ and $2 \times 10^{6} \mathrm{CFU} / \mathrm{mL}$. $* P<0.05$ compared when the microbial suspension was $2 \times 10^{4}, n=3$

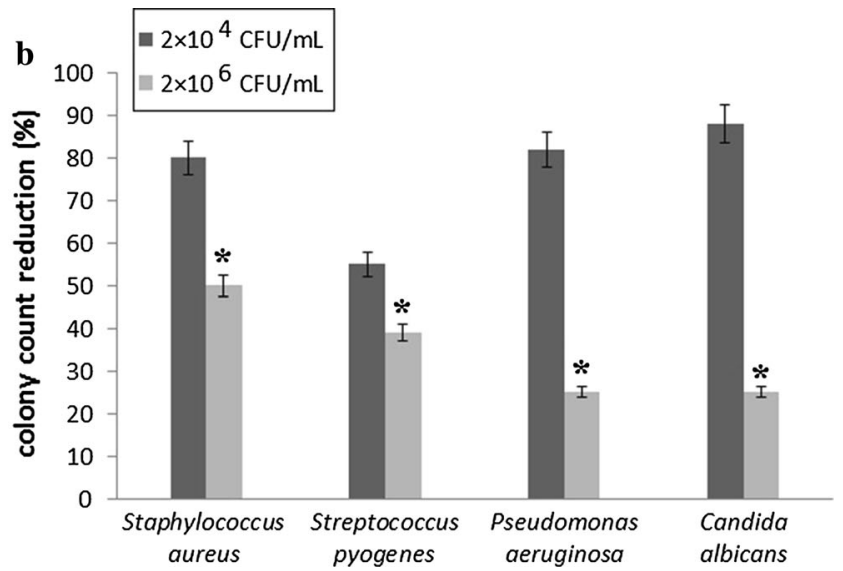

microbial suspension was variable, $2 \times 10^{4}$ and $2 \times 10^{6} \mathrm{CFU} / \mathrm{mL}$. $* P<0.05$ compared when the microbial suspension was $2 \times 10^{4}$, $n=3$

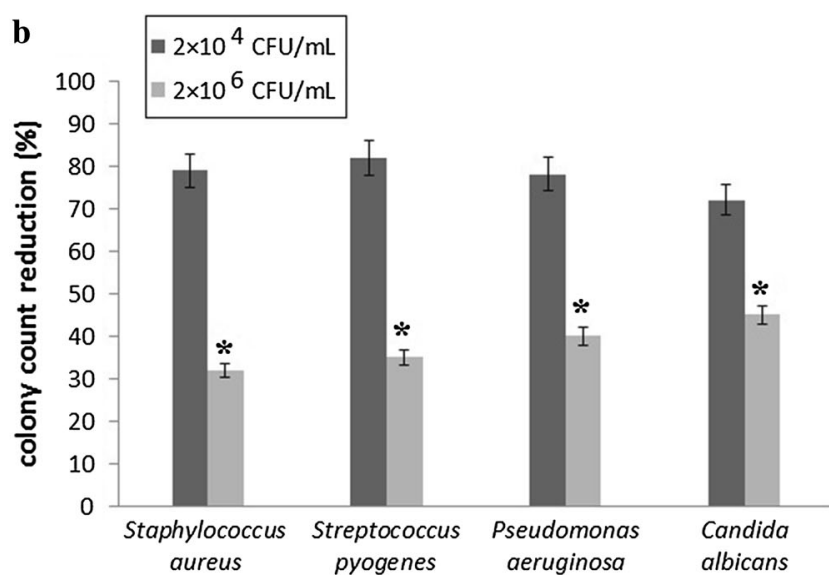

density of microbial suspension was variable, $2 \times 10^{4}$ and $2 \times 10^{6} \mathrm{CFU} / \mathrm{mL}$. $* P<0.05$ compared when the microbial suspension was $2 \times 10^{4}, n=3$ 


\section{Conclusion}

It can be concluded that all nano-based columns which investigated in this study could adsorb Staphylococcus aureus, Streptococcos pyogenes, Pseudomonas aeruginosa, and Candida albicans. Moreover, the combination of $\mathrm{CaSO}_{4}$ and $\mathrm{CaCO}_{3}$ nanoparticles led to better adsorption property. These adsorbent columns are good choice to remove hospital airborne microorganisms.

Acknowledgments There is no acknowledgment to declare. This study was granted by Pajoohesh Lab, Yazd, Iran, Grant Number: 2015-8.

\section{Compliance with ethical standards}

Conflict of interest There is no conflict of interest to declare.

\section{References}

Dancer SJ (2014) Controlling hospital-acquired infection: focus on the role of the environment and new technologies for decontamination. Clin Microbiol Rev 27:665-690

Daniel SCGK, Banu BN, Harshiny M, Nehru K, Ganesh PS, Kumaran S, Sivakumar M (2014) Ipomea carnea-based silver nanoparticle synthesis for antibacterial activity against selected human pathogens. J Exp Nanosci 9:197-209

Gomes F, Teixeira P, Oliveira R (2014) Mini-review: Staphylococcus epidermidis as the most frequent cause of nosocomial infections: old and new fighting strategies. Biofouling 30:131-141
Jung JH, Hwang GB, Lee JE, Bae GN (2011) Preparation of airborne $\mathrm{Ag} / \mathrm{CNT}$ hybrid nanoparticles using an aerosol process and their application to antimicrobial air filtration. Langmuir 27:10256-10264

Karottki DG et al (2013) An indoor air filtration study in homes of elderly: cardiovascular and respiratory effects of exposure to particulate matter. Environ Health 12:10-1186

Kelly KN, Monson JRT (2012) Hospital-acquired infections. Surgery (Oxford) 30:640-644

Lobdell KW, Stamou S, Sanchez JA (2012) Hospital-acquired infections. Surg Clin N Am 92:65-77

Lukasik J, Scott TM, Andryshak D, Farrah SR (2000) Influence of salts on virus adsorption to microporous filters. Appl Environ Microbiol 66:2914-2920

Ma K, Henderson B (2013) Ophthalmic air filtration practices in hospital and community settings and its role in modern day surgery. Invest Ophthalmol Vis Sci 54:811

Miaśkiewicz-Peska E, Łebkowska M (2011) Effect of antimicrobial air filter treatment on bacterial survival. Fibres Text East Europe 19:1

Pourakbari B, Rezaizadeh G, Mahmoudi S, Mamishi S (2015) Epidemiology of nosocomial infections in pediatric patients in an Iranian referral hospital. J Prev Med Hyg 53

Verdenelli M, Cecchini C, Orpianesi C, Dadea G, Cresci A (2003) Efficacy of antimicrobial filter treatments on microbial colonization of air panel filters. J Appl Microbiol 94:9-15

Wichmann J, Folke F, Torp-Pedersen C, Lippert F, Ketzel M, Ellermann T, Loft S (2013) Out-of-hospital cardiac arrests and outdoor air pollution exposure in Copenhagen, Denmark. PLoS ONE 8:e53684 